\title{
USE OF A SOFT AUTOPOLYMERIZING ACRYLIC RESIN FOR PROSTHETIC RESTORATION OF ORBITAL FACIAL DEFECTS
}

Pontes PN et al. Use of a soft autopolymerizing acrylic resin for prosthetic restoration of orbital facial defects, Annals Dent Univ Malaya 1997; 4: 27-30

\begin{abstract}
A technique for the fabrication of an orbital facial prosthesis using a soft autopolymerizing acrylic resin is presented. The material used has been found to be acceptable to most patients treated. The use of this material offers easy access for wound care and is ease to removal and maintenance of hygiene.
\end{abstract}

Key words: Occular Prosthesis, Prosthesis Design, Eye, Lid.

\section{INTRODUCTION}

The restoration of orbital defects presents a challenge in maxillo-facial prosthesis (1).

A prosthetic rehabilitation of a patient suffering from complete exenteration of the orbit and surrounding tissues will be greatly enhanced if a prosthesis is placed in it (2). An aesthetic prosthesis is very difficult to obtain and in some patients it may not be possible to duplicate the appearance and contour of the remaining normal eye and adjacent orbital structures. Structural reconstruction in conjunction with prosthetic replacement of the globe requires careful planning (3).

A technique for the fabrication of orbital facial prostheses in soft acrylic resin used in Maxillo-Facial Clinic, at Faculty of Dentistry of Ribeiro Preto - University of São Paulo is described.

\section{CASE REPORT}

\section{Patient Examination}

A 45-year-old well-nourished white woman was admitted at the Dental Materials and Prosthetic Department of Faculty of Dentistry of Ribeirão Preto - University of São Paulo (FORP-USP) for a definitive right side occular facial prosthesis.

The patient had been admitted for a tumour removal with surgical margins extended beyond the confinement of the orbit.The socket was then examined to determine the remaining structures.

\section{Impression Procedure}

1. The patient was seated on the dental chair with the defect of the eye facing up and parallel to the floor (Figure 1). The eyebrows and eyelashes were coated with Vaseline and the head draped with cotton towels to keep the impression material from flowing where it was not desired.

2. The patient was instructed to close her remaining eye and was cautioned to be relaxed during the impression procedure.
Paula Nuti Pontes

Maria da Gloria Chiarello de Mattos²

Marisa Semprini ${ }^{3}$

Marcelo Aparecido Vieira ${ }^{4}$

Ruberval Armando Lopes

Specialised in Oral Maxillo-Facial Prosthesis by University of São Paulo

2 Associated Professor at FORP-USP - Responsible for the Maxillo Facial Prosthetic Clinic at FORP-USP

3 Associated Professor at FORP-USP

4 Dental technician at FORP-USP

5 Full-Professor at FORP-USP

Correspondence to:

Dr Paula Nuti Pontes

P.S.N. Madge

Desa Palma Condominium C3-3

55.000 Kuala Lumpur

Malaysia

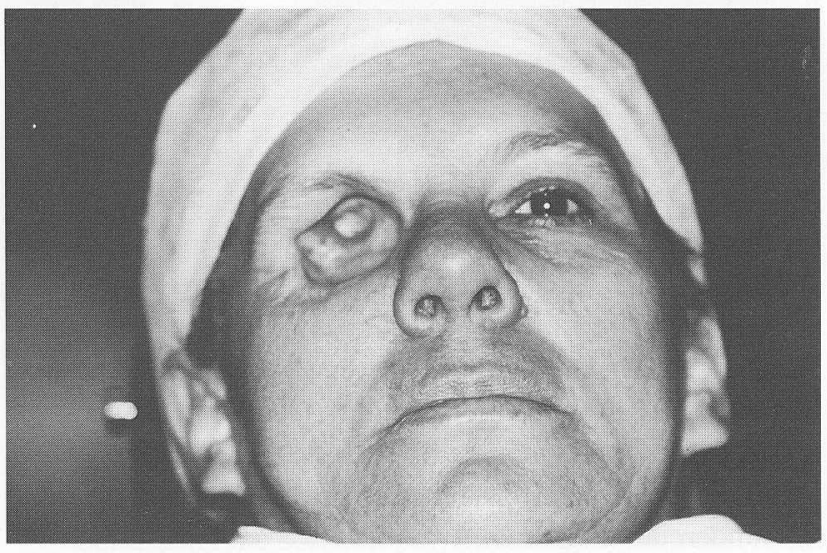

Figure 1. Surgical defect view.

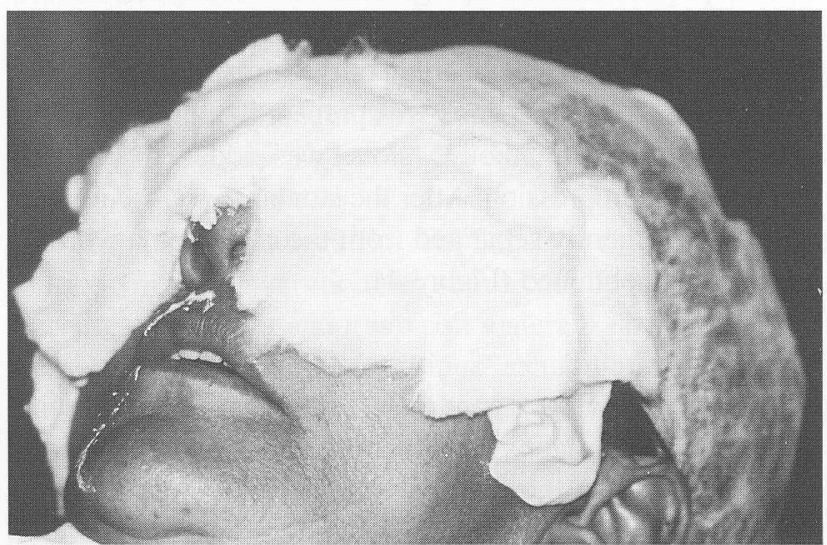

Figure 2. The hidrocolloid irreversible impression material is carefully spread over the surface of the skin. 


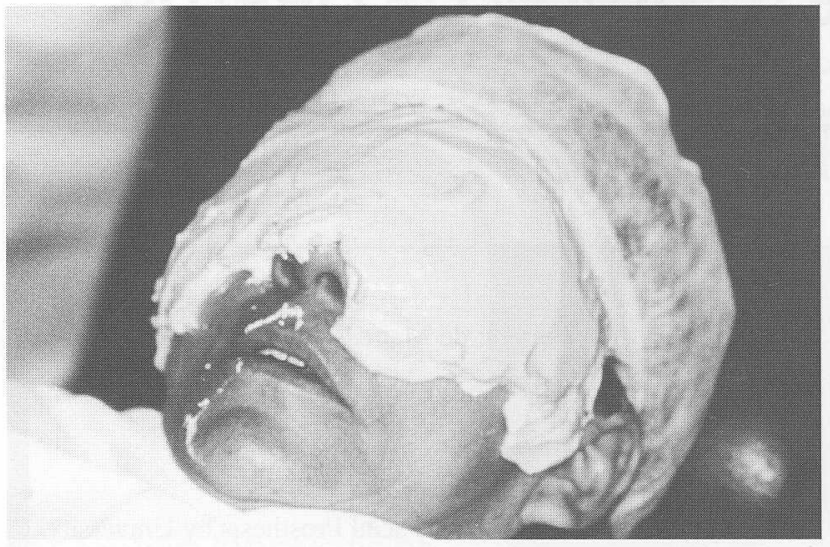

Figure 3. A quick setting plaster of Paris is made to reinforce the impression material

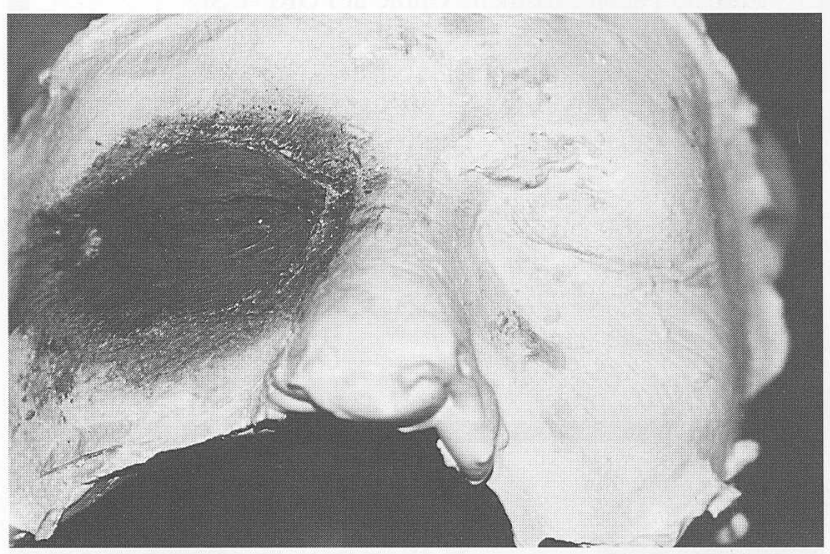

Figure 5. The modelling clay sculpture on the master cast.

3. An impression of the defect and surrounding structures was made with an irreversible hydrocolloid material, mixed with twice as much water as the proportion recommended by the manufacturer. Embed cotton was used over setting hydrocolloid irreversible material to provide retention as a reinforcing matrix (Figure 2).

4. A quick setting plaster of Paris reinforcement was laid over the impression material (4) blocking out extreme undercuts (Figure 3).

5. The reinforced impression was gently removed from the patient's face, keeping in mind the location of undercuts.

6. After removal, the accuracy of the impression was evaluated and a dental stone was prepared, poured slowly in the impression. Enough stone was added to properly cover the impression. After the stone has set, the impression was gently separated from the cast, then a working cast was obtained (Figure 4).

\section{Sculpting}

7. At the following appointment, sculpting of the periorbital tissues was made. Lid contours and periorbital tissues was shaped as those of the normal eye as closely as possible. All details were faithfully reproduced using modelling clay around the eye and molds, shaping the wrinkles and opening according to the contour of the remain-

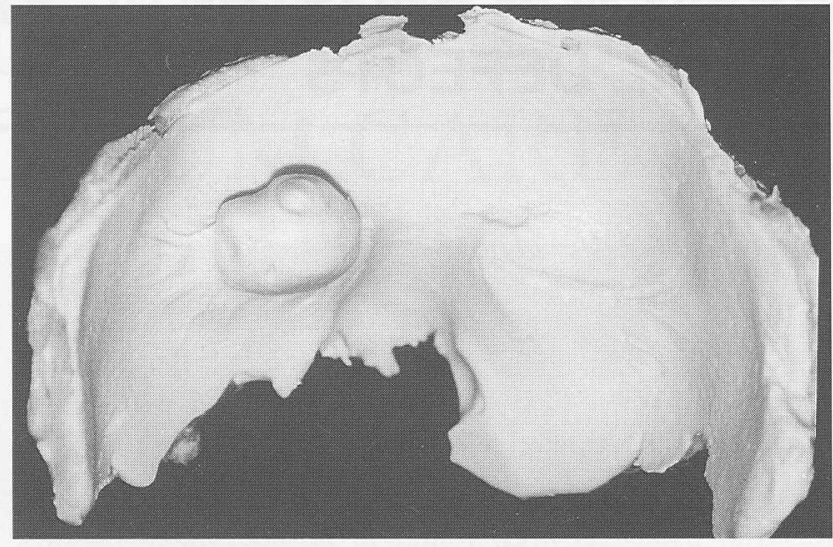

Figure 4. Working cast view.

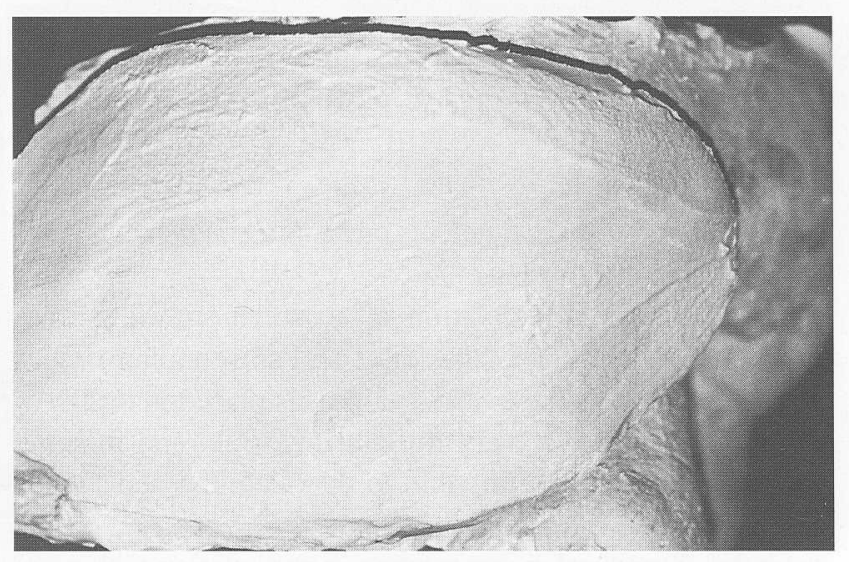

Figure 6. Artificial stone is poured over the modelling clay sculpture.

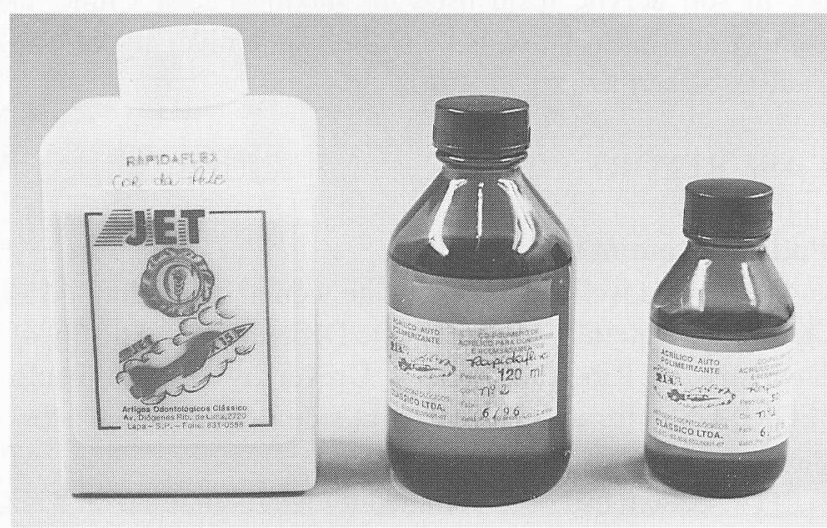

Figure 7. Rapidaflex material: a soft autopolymerizing acrilic resin.

ing eye (Figure 5).

8. The border of the master cast around the clay sculpture was lubricated with a thin layer of petroleum jelly, and stone was poured to form a counterdie (Figure 6). After the stone has set, the counterdie removed, and the modelling clay separated from the counterdie.

9. A hole was drilled through the deepest portion of the defect area on the cast to the exterior to facilitate the injection of fluid wax, thereby filling the portion previously occupied by the modelling clay.

10. The wax pattern was checked for fit and contour on the 


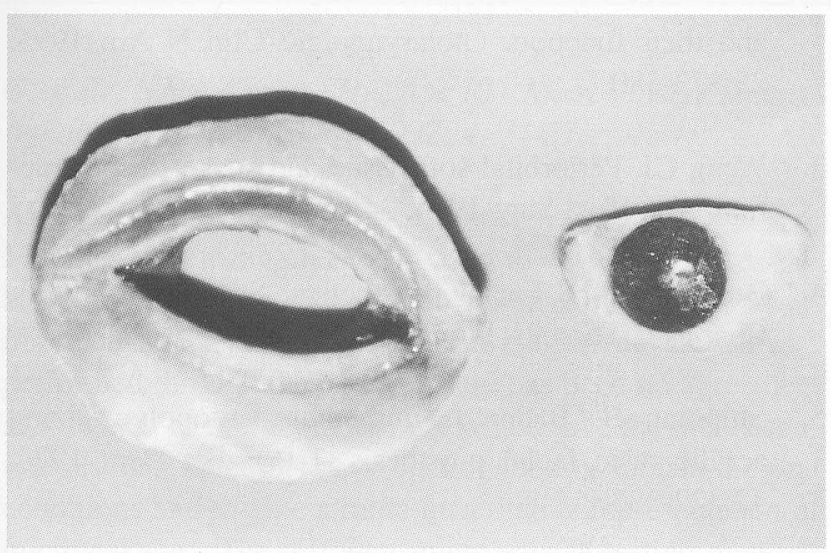

Figure 8. Stock plastic eye and the orbital facial prosthesis

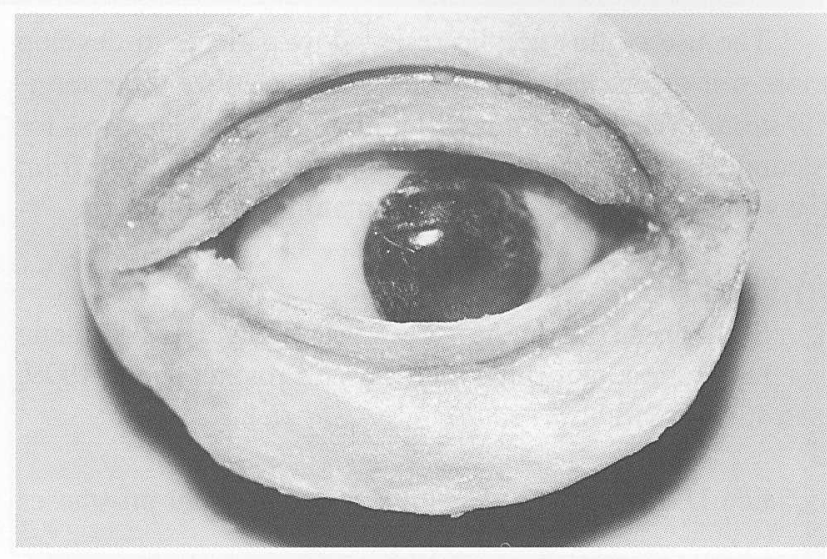

Figure 9. The stock plastic eye prosthesis is seated.

patient. The wax pattern was finished on the cast by extending about $1 \mathrm{~cm}$ beyond the margins of the defect.

11. The wax pattern was invested and then, eliminated in the boiling water.

12. Soft autopolymerizing acrylic resin (Rapidaflex - Clássico Artigos Odontológicos Ltda - Brazil Figure 7) was prepared by mixing 3 parts of polymetacrylate powder, 1 part of methylmetacrylate fluid and 2 parts of the plasticiser liquid that render the acrylic resin in a soft material. It was then, intrinsically coloured to the patient's basic skin shade. The mixture was placed in the flask. The cured soft autopolymerizing acrylic resin was removed and trimmed to secure a smooth border to the predetermined margin.

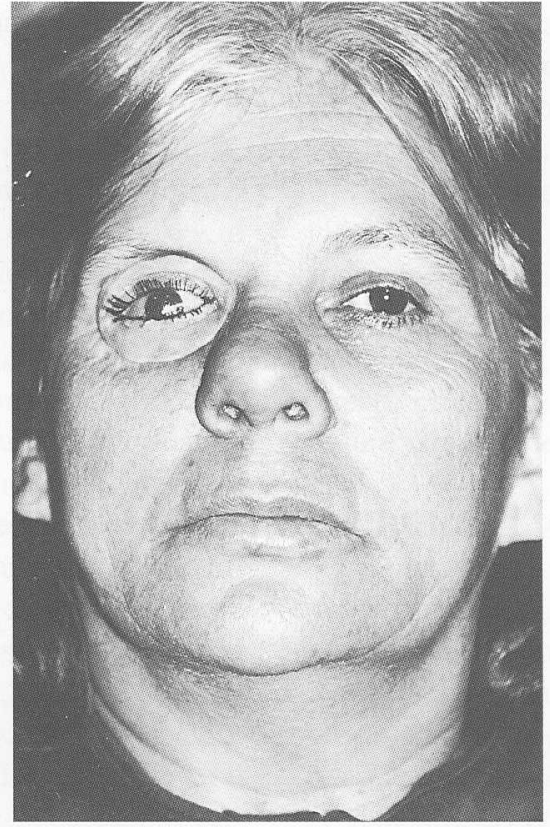

Figure 10. The completed prosthesis in place.

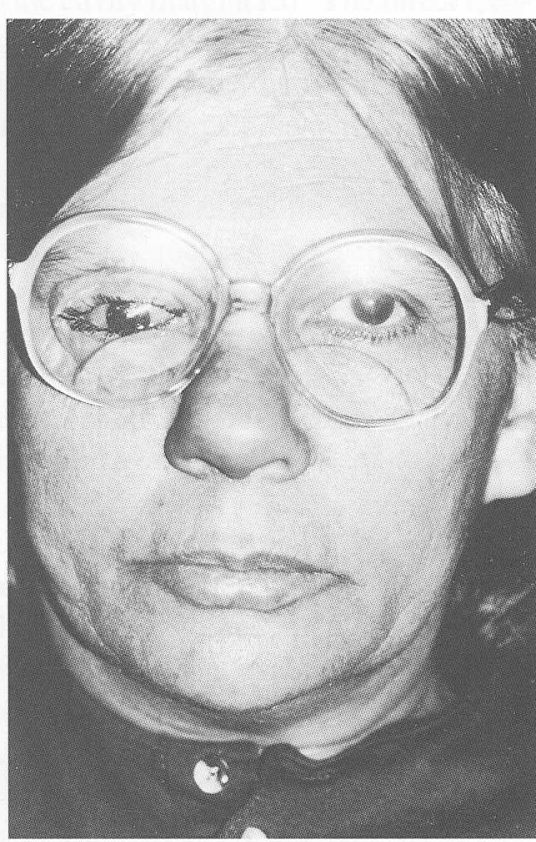

Figure 11. The completed prosthesis in place.
13. Selecting the eye: a standard plastic eye of the shape and colour of the normal eye was selected, and it was reduced to the proper size. All sharp edges were removed (Figure 8).

14. The eye was inserted into the soft acrylic resin portion of the prosthesis from the back side and then the artificial eye was placed (Figure 9). A ready supply of processed curved natural hair was used as eyelashes, and were placed in an upward position on the upper eyelid and in a downward position on the lower lid (Figure 10).

15. The prosthesis is now ready for placement in the orbital defect of the patient (Figures 11).

\section{DISCUSSION}

The material used in this work has been found to be acceptable to most patients treated. The technique utilising the elastic property of the soft autopolymerizing acrylic enable the usage of undercuts in the defect primarily for retention. As observed by Shifman et al.(1), the prosthesis is light, yet rigid enough to retain its form and not collapse.

The use of this resin prosthesis easily allows the max- illofacial prosthodontist to modify and replace it at a relatively low cost, as observed by Shipman \& Bader (5).

Comparing the soft autopolymerizing acrylic resin to the poly methyl methacrylate resin, largely used in maxillofacial prosthodontics, it was observed that the first one presents the following advantages:

1. The prosthesis is light and aestheticaly acceptable, because may mach to the skin shades.

2. The softness gives to the orbital prosthesis a natural appereance.

As disadvantadges it was observed that the soft autopolymerizing acrylic resin should not be hight polished, because it has pores and it is a soft material. This in fact, may be responsable for organic residue accumulation and growing of microorganism, in case that the orbital prosthesis is not properly kept cleaned.

\section{CONCLUSIONS}

The technique for restoration of orbital defect using the autopolymerizing acrylic resin is described. 
The use of this acrylic resin allow patients to develop more self assurance in the later management of their surgical stomas. The use of this material offers feasible access for wound care and the prosthesis can be easily removed from the socket and cleaned hence maintaining good hygiene.

\section{REFERENCES}

1. Shifman A, Levin AC, Levy M, Leply JB. Prosthetic restoration of orbital defects. J Prosthet Dent 1979, 42:543-546.

2. Lee D. Design and development of external prostheses and their function. Otolaryngolgic Clin N Am 1995, 28:373-380.

3. Weng CJ. Periorbital soft-tissue and socket reconstruction. Ann Plast Surg 1995, 34:457-462.

4. Bulbulian AH. Facial prosthetics. Springfield, 1973, Charles C Thomas, Publisher, pp.77-85.

5. Shipman B, Bader J. Immediate autopolymerizing acrylic resin facial prosthesis. J Prosthet Dent 1979, 42:322-326. 